\title{
¿Qué podemos pedir a una teoría de la justicia? Algunas consideraciones acerca de un debate entre Amartya Sen y John Rawls
}

\author{
What can we demand from a theory of justice? \\ Some remarks about a debate between Amartya Sen \\ and John Rawls
}

FRANCESCO BIONDO

Università di Palermo

RESUMEN. En este trabajo intento exponer las tesis de Sen sobre las características que demandamos a una teoría satisfactoria de la justicia, y sus críticas al modelo «trascendental» de teoría, que según él es lo que Rawls persigue. Según Sen, este modelo es inaceptable por ser inalcanzable e innecesario; lo que en nuestra práctica argumentativa intentamos lograr son juicios comparativos entre situaciones reales, y no sistemas completos de proposiciones acerca de ideales de la sociedad justa. Intentaré argumentar que el enfoque metaético de Sen es débil por dos razones: no ofrece una reconstrucción adecuada de la teoría de Rawls, equivocándose sobre su carácter «completo», y no explica de qué manera los juicios comparativos de valor entre dos situaciones sociales no sean el resultado de una teoría «trascendental» de la justicia. Me propongo, entonces, solucionar el problema, presentando una mirada trascendental de las cuestiones de justicia, pero, al mismo tiempo, pluralista e incompleta.

Palabras clave: Teorías de justicia distributiva, Rawls, Sen, pluralismo moral, particularismo moral.
ABstract. In this paper I try to revise Sen's thesis about the «transcendental» nature of Rawls' theory of justice. According to Sen transcendental theories of justice are unnecessary. What we aim at is to justify a series of comparative judgements about two or more states of affairs. We do not strive, unlike Rawls, to form a complete system of moral principles that backs an «ideal just society». I try to show that Sen's «comparative» account is weak. First of all, Sen does not offer a fair interpretation of Rawls' theory. In particular, he is wrong when he depicts Rawls' justice as fairness as a complete and transcendental moral doctrine. Secondly, Sen overlooks the fact that in order to justify comparative evaluations of states of affairs we must assume as valid a particular moral doctrine. Finally I try to solve the problem about the contrast between transcendental and comparative account by offering a transcendental outlook to questions of justice that is, at the same time, pluralist and incomplete.

Key words: Theories of distributive justice, Rawls, Sen, moral pluralism, moral particularism. 
Una de las ventajas de ser un pensador muy respetado y famoso es, sin duda, la oportunidad de plantear preguntas incómodas. Lo que normalmente los filósofos hacen es discutir, a menudo con demasiada pasión, sobre algunas proposiciones de otras teorías: en especial si éstas son contradictorias con otras tesis expuestas en la misma teoría, si son poco claras en sus premisas o si producen consecuencias inaceptables. Pero en cambio es más raro encontrar preguntas como la que Amartya Sen nos plantea en un reciente artículo: «¿Qué pedimos a una teoría de la justicia?» ${ }^{1}$, es decir: ¿qué es lo que intentamos conseguir cuando nos adentramos en un debate sobre las virtudes de las numerosas teorías de la justicia, que hoy en día encontramos en el debate filosófico? La pregunta es incómoda porque nos enfrenta a cuestiones metaéticas (como si existen valores objetivos, si es posible conocerlos, si son plurales e inconmensurables, o si podemos alcanzar una unidad de medida común, etc.) a las que a menudo no conseguimos encontrar una respuesta unívoca, y, por lo tanto, intentamos elaborar doctrinas que sobre temas particulares puedan encontrar el respaldo de autores con diferentes posturas. En este trabajo, mi intención es exponer las tesis de Sen sobre las características que demandamos a una teoría satisfactoria de la justicia, y sus críticas al modelo «trascendental» de teoría, que según él es lo que Rawls persigue. Según Sen, este modelo es inaceptable por ser inalcanzable e innecesario; lo que en nuestra práctica argumentativa intentamos lograr son juicios comparativos entre situaciones reales y no sistemas completos de proposiciones acerca de ideales de la sociedad justa. Intentaré argumentar cómo el enfoque metaético de Sen es débil por dos razones: no ofrece una reconstrucción adecuada de la teoría de Rawls, equivocándose sobre su carácter «completo», y no explica de qué manera los juicios comparativos de valor entre dos situaciones sociales no sean el resultado de una teoría «trascendental» de la justicia. Me propongo, entonces, solucionar el problema, presentando una mirada trascendental de las cuestiones de justicia, pero, al mismo tiempo, pluralista e incompleta.

\section{Dos enfoques metaéticos a las cuestiones de justicia}

Según Sen, tenemos dos modelos diferentes de evaluación de las teorías de la justicia: el trascendental y el comparativo.

El primero, planteado por Rawls, en el que se intenta identificar la estructura social «perfectamente justa», es decir, las características de un conjunto de instituciones y de principios que deberían realizar «una sociedad completamente justa». La meta de la teoría de la justicia como equidad consiste en averiguar las condiciones sociales y los principios de justicia que permitan garantizar la paridad de poder entre las partes en una relación contractual en la que existe una situación de ignorancia de las preferencias individuales: «el ejercicio de la imparcialidad está orientado por entero a la identificación de principios adecuados a una sociedad completamente justa, y al aislamiento de las necesidades institucionales de cara a la estructura básica de dicho tipo de sociedad» (WTJ, p. 217). A este enfoque lo denomina Sen «trascendental», porque éste se detiene a delimitar las condiciones de una sociedad perfectamente justa, y no da elementos para evaluar los progresos de sociedades que se sitúan alejadas de estos ideales. Pero hay otra forma, más útil para evaluar y solucionar las condiciones de injusticia, que, según Sen, es la que nos ofrecen los enfoques «comparativos» de las cuestiones morales.

La naturaleza polémica de la división de las posiciones doctrinales, entre teo- 
rías trascendentales y teorías comparativas, aparece clara en esta extensa cita del propio Sen:

Con el fin de ilustrar el contraste aquí implícito, bien podría resultar que, desde una perspectiva comparativa, la introducción de políticas sociales que abolan la esclavitud o bien que erradiquen el hambre extendida, o eliminar el creciente analfabetismo, pueden mostrarse como arrojando un resultado de mejora en la Justicia. Pero la instauración de dichas políticas podría colocar a las sociedades involucradas muy alejadas de los requisitos trascendentales de una sociedad completamente justa, del mismo modo (en la medida en que tendría otras exigencias en relación con libertades igualitarias, equidad distributiva, y demás). La gran diferencia existente entre lo que es «justo» y lo que es «injusto», que es lo que resultaría de una teoría trascendental de la Justicia, dejaría incluso a la sociedad correspondiente a la parte de lo «injusto», tras su reforma, y, bajo una perspectiva comparativa, a pesar de lo que pueda parecer, como representante de un cambio que produce un incremento en la Justicia (WTJ, p. 217).

El propio Sen admite que esta división puede resultar demasiado rápida, y no suficientemente ponderada. Es necesario preguntarse si, por el contrario, al final no sea necesario y, tal vez, suficiente, seguir un enfoque trascendental para hacer comparaciones morales entre dos situaciones de hecho. Al fin y al cabo, admite Sen, parece que cuando nos preguntamos cuál sea la más justa entre dos sociedades tenemos en cuenta las respectivas distancias entre estas sociedades y un modelo ideal de sociedad justa. En este caso, admitiríamos que cuando comparamos dos órdenes sociales aceptamos una unidad de medida moral, que no es algo más que lo que consideramos que es justo en un determinado orden social. La menor distancia entre un orden real y el orden ideal nos indicaría que aquél, el menos distante, sería la sociedad más justa, entre las dos. También podría ser que cuando hacemos una comparación sea necesario, aunque no sea suficiente, tener una idea de lo que sea una sociedad justa, al menos si intentamos justificar nuestra valoración. ¿Entonces las consideraciones de justicia trascendental son suficientes, o por lo menos necesarias, cuando comparamos los valores morales de dos órdenes sociales? A estas dos posibles objeciones Sen contesta con un rotundo no.

En primer lugar, no podemos considerar suficiente un enfoque trascendental para realizar comparaciones morales entre dos órdenes sociales. Hay muchas dificultades para ordenar las distancias que las sociedades reales mantienen entre ellas y el ideal de sociedad justa. Sen nos indica tres: en primer lugar pueden existir diferentes puntos de partida, que corresponden a diferentes teorías de la justicia. Estas diferentes teorías pueden tener en cuenta diversos elementos de valor, algunas de ellas los derechos de no interferencia, otras la distribución de recursos, otras las oportunidades, otras las capacidades, otras incluso las utilidades. En segundo lugar, no hay un acuerdo sobre cómo medir las distancias entre un punto de partida y el ideal; es decir, no está claro cuánto sea de largo el camino para realizar una sociedad justa. Esto, para Sen, no es un problema para una teoría trascendental de la justicia: «algunos de entre los trascendentalistas puros se opondrían vehementemente incluso a coquetear con la idea de valoraciones comparativas y clasificatorias, y muy bien pudiera ser que evitaran en absoluto conclusiones de tipo relacional» (WTJ, p. 220). En último lugar, aunque estuviéramos de acuerdo sobre las características del mejor orden social, este acuerdo no nos daría ningún criterio para evaluar, y ordenar, otros tipos de sociedades. Es posible que después de determinar lo que es lo mejor, no sepamos cómo ordenar las posibles alternativas. Como afirma el propio Sen: «la 
búsqueda de la Justicia transcendental es un ejercicio que resulta atractivo de por sí, pero, independientemente de que pensemos en la trascendencia en términos de "bondad" gradual o bien dentro del marco de su mayor grado, "lo mejor", esto no nos dice mucho respecto de los méritos comparativos de gran parte - de hecho, suelen ser la mayoría- de los distintos logros de la Sociedad» (WTJ, p. 221).

$\mathrm{Si}$ estamos de acuerdo en que un enfoque trascendental de las teorías de la justicia no nos proporciona ninguna unidad de medida para comparar dos órdenes sociales, podríamos aceptar tal enfoque como una condición necesaria, aunque no suficiente, para comparar estos órdenes sociales. Esta hipótesis simplemente afirma que si intentamos comparar dos elementos de una determinada clase de objetos, debemos tener en cuenta un criterio que nos indique cuál puede ser el ejemplo mejor de esta clase de objetos. En nuestro caso, si supiéramos cuál es la sociedad más justa entre dos tipos distintos de sociedades, podríamos determinar las características de una sociedad idealmente justa. Según Sen, tampoco esta hipótesis es aceptable. Es cierto que muy a menudo si intentamos ordenar algunas alternativas podemos tener en cuenta un modelo ideal de lo que es bueno. Pero esto pasa únicamente si estamos convencidos de que podemos producir órdenes completos de alternativas, lo que Sen llama «clasificaciones bien ordenadas». En este caso sí sería necesario determinar siempre qué es lo mejor, idealmente, antes de decidir cuál es la mejor entre dos alternativas; si no, no podríamos elaborar teorías del valor que fueran completas y coherentes. Este enfoque «totalista» es lo que, según Sen, persigue Rawls y los que opinan que «la supervivencia de la incompletitud es, en ocasiones, vista como un defecto para una teoría de la Justicia, uno que pone en cuestión los asertos po- sitivos que una teoría de este tipo realiza» (WTJ, p. 223). Sin embargo, una aceptable teoría moral no necesita un enfoque «totalista» a las comparaciones. Para comparar dos o más alternativas no es necesario producir un sistema de evaluación que pueda ordenar todas las alternativas posibles. Al final, podemos estar de acuerdo en considerar como mejor un estado que asegure universalmente niveles mínimos de asistencia sanitaria, respecto a otro que no asegura estos niveles, sin decidir cuál sea el nivel impositivo máximo más justo. Muy a menudo no podemos ordenar de una forma completa todas las alternativas a las que nos enfrentamos; nos puede faltar información relevante para tomar una decisión, o no estamos de acuerdo en ponderar en algunos casos dos, o más, valores en conflicto. $\mathrm{Y}$ desde luego podemos decidir que algunas de estas alternativas son peores, o mejores, aunque no sepamos cómo ordenar las otras. Nos parecen relevantes, sobre todo para los filósofos del derecho comprometidos en evaluar la aceptabilidad de las ponderaciones entre derechos, las palabras del propio Sen: «podríamos reconocer la posibilidad de que las libertades de diversas personas pudieran, hasta cierto punto, entrar en conflicto entre sí (de tal manera que cualquiera de entre las correctamente engarzadas demandas de libertad igualitaria podría encontrar dificultades para desarrollarse), y, sin embargo, estar profundamente de acuerdo en que la tortura de personas bajo acusación sería una violación injusta de la libertad y que dicha injusticia exige una rectificación urgente» (WTJ, p. 224).

Hay otra razón para aceptar formas incompletas de razonamiento en nuestras argumentaciones morales. Según Sen es posible que existan conflictos entre las teorías de la justicia distributiva. Frente a una decisión concreta (¿a quién dar un trozo de tarta?) partidarios de diferentes 
doctrinas de la justicia (utilitaristas, libertarios, rawlsianos, comunitaristas) pueden dar respuestas diferentes, y no podemos elegir entre una de ellas. Esta afirmación de pluralismo metaético extremo parece sorprendente para un autor que ha dedicado una parte considerable de su obra a criticar casi todas la teorías de la justicia distributiva (desde el utilitarismo en sus diferentes versiones hasta las últimas concepciones del comunitarismo, pasando por Rawls y Nozick), y que ha elaborado una doctrina alternativa. Pero no debemos caer en la trampa de imputar a Sen posiciones que él no ha mantenido (aunque su planteamiento metaético no sea muy claro, como vamos a intentar demostrar). Este autor no parece ser partidario de una forma de pluralismo metaético extremo, es decir, considera alcanzable un acuerdo entre órdenes de valores diferentes e inconmensurables, al entender que el dominio de la ética es un ámbito donde hay posibilidad de encuentro entre diferentes doctrinas. Por el contrario, es posible que nuestros órdenes de valores se puedan entremezclar con otros, produciendo sistemas «parciales» de evaluación que nos permitan evaluar las medidas alternativas y especialmente lo que es necesario hacer para reducir las injusticias y mejorar las condiciones de vida. Especialmente cuando nos enfrentamos a cuestiones de justicia distributiva internacional podemos averiguar que sí que se puede razonar sobre el modo de reducir las injusticias aunque no se cumplan todas las condiciones, en primer lugar las institucionales, necesarias para realizar un mundo «justo». Si así no fuera, estaríamos condenados a considerar las cuestiones internacionales como asuntos en los que se aplican sólo consideraciones humanitarias, o argumentos de equilibrio entre potencias, pero nunca se podría aplicar ningún tipo de doctrina de la justicia. Este resultado, según Sen, se produce cuando el propio Rawls deja de aplicar cualquiera principio de justicia al ámbito internacional, dejando la cuestión de la ayuda a los pueblos más pobres a la suerte de la aplicación de los principios de intervención humanitaria. La amarga conclusión es que «el vehículo rawlsiano de Justicia que nos conduce con rapidez hacia adelante en pos de algo de la misma en un Mundo carente de ella, permanece estacionado e inamovible en el frío amanecer de un Mundo sin Estado Global» (WTJ, p. 227). Entonces, el precio que se paga al intentar lograr teorías morales completas y coherentes que intentan delimitar lo que es máximamente (o idealmente) justo, según un enfoque trascendental a las cuestiones de justicia, es dejarnos sin argumentos cuando tenemos que ordenar alternativas concretas que se sitúan lejos de nuestros ideales. Es un precio, para Sen, demasiado alto, cuando con nuestra experiencia podemos alcanzar acuerdos sobre valoraciones de medidas que sí puedan mejorar la vida, aunque no realicen nuestros ideales de justicia. Lo que está en peligro, nos advierte Sen, es el mismo ideal rawlsiano de un debate público sobre las cuestiones de justicia.

«La deliberación pública puede ser útil e importante al mismo tiempo en la búsqueda de la reforma de las instituciones (incluso cuando la totalidad de las reformas institucionales necesitadas de perfeccionamiento no pueden llevarse a cabo) y en el examen de lo que puede ser efectuado para reducir la injusticia - una cuestión básica en el enfoque comparativo de la Justicia - aún y cuándo no se encuentran en juego la totalidad de las instituciones apropiadas. Una aproximación comparativa no rawlsiana a la Justicia (antes bien que trascendental) puede ser una buena base conceptual para un razonamiento público - fundamentalmente rawlsiano- de esta clase» (WTJ, p. 228).

Pero ¿es posible argumentar razonablemente sobre cuestiones de justicia, si 
no existen instituciones justas? Según Sen sí, ya que no debemos dramatizar el asunto del pluralismo entre las doctrinas. En primer lugar, como hemos visto antes, es posible que diferentes doctrinas valoren de la misma manera dos alternativas, aunque estén en desacuerdo sobre otros asuntos. En segundo lugar, el hecho mismo de que se descubran puntos de acuerdo hace que aumente el ámbito de asuntos sobre los que se puedan ofrecer valoraciones congruentes. Lo importante es aceptar el punto de partida de la argumentación: que una doctrina de la justicia no tiene que mantenerse callada si no puede ofrecer una respuesta unívoca a cualquier otro asunto al que se enfrente. A pesar de no tener una doctrina coherente y completa, se pueden elaborar argumentos aceptables sobre determinadas cuestiones de justicia (WTJ, pp. 235-236).

La propuesta teórica de Sen abre la puerta a dos cuestiones, entre otras muchas.

En primer lugar, ¿Es la doctrina rawlsiana un ejemplo de enfoque trascendental a los asuntos de justicia? ¿O, por el contrario, Sen intenta construir un modelo teórico que verdaderamente ni siquiera el mismo Rawls aceptaría?

En segundo lugar, ¿El modelo comparativo de valoración no necesita realmente de un ideal que nos proporcione un modelo de sociedad justa? Y si, al final, es necesario que nuestras valoraciones de los méritos morales entre dos alternativas se fundamenten en las concepciones de la justicia o del bien, entonces ¿cómo podemos tener en cuenta el pluralismo de estas doctrinas? ¿Se trata sólo de averiguar si podemos o no podemos alcanzar acuerdos incompletos, sin considerar las características metaéticas de las doctrinas en cuestión? ¿O podemos, a pesar de lo que parece pensar Sen, ofrecer un modelo metaético de doctrina moral?

\section{2. ¿Es la doctrina rawlsiana realmente «trascendental»?}

Aunque Rawls sea el objetivo más polémico del ensayo de Sen resulta sorprendente el hecho de que en el texto no abunden referencias a las obras del filósofo americano, al menos sobre el carácter exhaustivo de su doctrina. La naturaleza trascendental del enfoque de justicia como equidad está patente, según Sen, en varias ocasiones. En primer lugar, el propio funcionamiento de las instituciones representativas, desde las asambleas constitucionales hasta las cámaras legislativas y los propios tribunales «lleva a nuevas decisiones sociales en posteriores estadios del sistema rawlsiano, como por ejemplo a través de una legislación adecuada (a lo que Rawls llama "el estadio legislativo"). La secuencia continúa paso a paso siguiendo directrices firmemente establecidas, con un elaborado y característico despliegue de logros sociales completamente justos» (WTJ, p. 217).

El valor moral de las instituciones públicas, y de sus decisiones, depende entonces de su coherencia con lo que se ha decidido en el estadio original bajo el velo de ignorancia. Según Sen, la doctrina de la justicia como equidad se fundamenta en las deliberaciones que se toman en aquel ficticio momento, y por esto «la voz de una persona cuenta porque él, o ella, está involucrado directamente en el contrato social, que "regulará las instituciones" de la sociedad de la cual él o ella, es miembro» (WTJ, p. 229) ${ }^{2}$. Esta forma de reducción de todos los argumentos posibles a los que se presenten en la posición original no evita que el enfoque rawlsiano sufra una especie de «localismo» en la argumentación. Citando la famosa tesis de la aplicación del artificio del estadio original sólo a sociedades cerradas, Sen conecta la naturaleza presuntamente completa del enfoque de la justi- 
cia como equidad con el reconocimiento, por el mismo Rawls, de su alcance limitado (WTJ, p. 233) ${ }^{3}$. Formular teorías trascendentales, y por lo tanto, completas, de la justicia paga, como hemos visto antes, un alto precio: limitar la aplicación de estas teorías a las sociedades en las que existen las instituciones necesarias para realizar una sociedad justa (WTJ, p. 227$)^{4}$.

En mi opinión ambas tesis están equivocadas. No es cierto ni que a través de los cuatro estadios de reducción del velo de ignorancia se cumplan los principios de justicia, ni que la decisión de no presentar principios similares de justicia se deba atribuir al carácter «trascendental» y cerrado de la propuesta teórica de Rawls. Al contrario, una limitada eficacia de estos principios parece el precio que el autor estaba dispuesto a pagar por mantener abierta su doctrina a cuestiones internacionales. Antes de empezar, quería aclarar que estas notas tienen, sobre todo, un valor exegético, no intento defender la teoría rawlsiana in toto, simplemente me gustaría poner de manifiesto algunos elementos, que Sen no ha tenido en cuenta. Es cierto que se trata de interpretaciones, que ahora no pueden ni siquiera ser defendidas, o rechazadas, por el propio Rawls. Pero, como ya he intentado demostrar ${ }^{5}$ en otra ocasión, la doctrina de la justicia como equidad es tan compleja al estar abierta a múltiples malentendidos. Que sea una doctrina «completa» es, en mi opinión, uno de éstos. Veamos por qué.

En primer lugar, parece que el propio Rawls no considere su teoría como «completa», al menos en el sentido que le atribuye Sen. Al hablar de la modalidad de aplicación de su doctrina de la justicia como equidad en determinados procesos políticos de toma de decisiones, él admite que el resultado no puede más que ser «indeterminado», es decir, no se puede decir cuál, de las posibles medidas coherentes con los límites establecidos por los principios de justicia, sea la mejor, la más justa o la más eficaz:

«a menudo dicha prueba no está determinada: no está claro, a menudo, cuál de las distintas instituciones, o de los logros económicos y sociales, sería elegido. Pero cuando esto sucede de tal modo, la Justicia está hasta el mismo extremo indeterminada del mismo modo. Las instituciones dentro del orden permitido son justas por igual, significando con ello que son susceptibles de elección; son compatibles con todas las restricciones de la teoría. Así, en muchos asuntos de la política económica y social debemos retroceder a una noción de Justicia procedimental cuasi pura: las leyes y las políticas son justas sólo en el caso de que se hallen dentro del orden permitido, y la asamblea legislativa, de algún modo legitimada por una constitución justa, las ha promulgado, de hecho. Esta indeterminación dentro de la teoría de la Justicia no es en sí misma un defecto. Es lo que deberíamos esperar» (TJ, p. 176).

Pues bien, Sen podría responder que una teoría puede ser «totalista», es decir, «completa», y al mismo tiempo indeterminada. Esta doctrina podría limitarse a afirmar: «no importa cuál sea la medida más eficaz para realizar los dos principios de justicia, lo importante es eliminar las medidas que sean incoherentes con los dos principios». Pero, ¿con cuál de los dos principios? Como bien es sabido, Rawls pone un orden lexicográfico entre los dos principios, pero él mismo admite que en condiciones reales no es siempre posible presentar reglas de prioridad entre el primer y el segundo principio.

«Ya que lo comentamos, dichos reglas y principios de prioridad, son, sin lugar a dudas, incompletos. (...) De modo que la clasificación de los principios de la Justicia en la teoría ideal, devuelve el reflejo y guía la aplicación de los mismos en situaciones no-ideales. Señala, en primer lugar, con qué limitaciones hay que vérselas. En los casos más enrevesados y extremos de la teoría no-ideal, esta prioridad de las reglas fallará sin lugar a dudas; y, 
de hecho, podríamos no ser capaces, en modo alguno, de encontrar una respuesta satisfactoria» (TJ, p. 267) ${ }^{6}$.

Entonces, no sólo la teoría es, con palabras del propio Rawls, indeterminada, sino que es indeterminado el orden de prioridad. Las incertidumbres sobre el carácter, si no completo, al menos coherente, de la doctrina de la justicia como equidad, se suman a lo que me parece una diferencia de alcance de los dos principios de justicia. Según Rawls, sólo el primer principio puede ser constitucionalizado, el segundo no. La razón expuesta es que mientras está claro cuándo se violan las libertades básicas, lo mismo no se puede decir de las violaciones del principio de diferencia.

«A menudo, lo mejor que podemos decir de la ley o la política en cuestión, es que al menos no es claramente injusta. La aplicación del principio de diferencia de manera precisa requiere normalmente información adicional de la que podemos esperar disponer $\mathrm{y}$, de cualquier modo, más que la mera aplicación del primer principio. Es con frecuencia perfectamente claro y evidente cuándo las libertades individuales están siendo violadas. (...) Así, la prioridad del primer principio de Justicia respecto del segundo queda reflejada en la prioridad de la convención constitucional respecto del estadio legislativo» (TJ, pp. 174-175).

No pretendo en esta ocasión criticar la postura de Rawls sobre el asunto del alcance y de la garantía legal de los principios de justicia. Intento sólo poner de relieve el extraño caso de una teoría indeterminada (que sin embargo, según Sen, se presenta como «totalista») que intenta derivar todas sus proposiciones desde un artificio mental, la posición original, y que deja de lado las complejidades que las situaciones no ideales nos ofrecen. Por el contrario, creo que la doctrina de la justicia como equidad constituye un intento de ofrecer una reconstrucción de nuestras argumentaciones morales a par- tir de una dialéctica entre el nivel ideal, de la teoría, y el nivel concreto de las decisiones que tomamos bajo la ignorancia, la falta de recursos o la influencia de culturas no igualitarias. Por esta razón, la doctrina de la justicia como equidad diferencia entre el alcance y la garantía legal de los dos principios de justicia. Entonces, no creo que, tal y como está formulada, la teoría de Rawls pueda ser considerada «trascendental» en su resultado, aunque puede que lo sea en su origen, en el intento de seleccionar las informaciones relevantes para formular los principios de justicia. Pero, como ya hemos visto, esto no hace que la doctrina de la justicia como equidad sea «determinada» o ajena a problemas de valoración de medidas o situaciones concretas ${ }^{7}$.

Si bien podemos aceptar las clarificaciones sobre lo que el propio Rawls opinaba de su teoría, en particular su carácter indeterminado, se mantiene indiscutible su alcance limitado y su naturaleza cerrada, o bien dependiente de algunas condiciones institucionales. En este caso, como he dicho antes, Sen recupera una antigua polémica con Rawls, que se remonta a Inequality reexamined. Pero, no me parece claro el planteamiento de las críticas de Sen. Él parece no distinguir entre dos niveles de análisis: el nivel epistemológico y el nivel político. Mientras sí se puede argumentar que el constructivismo kantiano propuesto por parte de Rawls no está bastante claro en su postura metaética (es decir, no clarifica la naturaleza de nuestros juicios morales, si son fruto de convenciones que se desarrollan en una sociedad liberal o si son intuiciones morales que están en equilibrio reflexivo con otras intuiciones), creo que la misma crítica no se puede formular respecto a su justificación contractualista. Ésta se mantiene en el marco de las teorías clásicas (como la de Hobbes, Locke, Kant), que intentaban averiguar las condiciones mínimas para 
que se pueda llegar a un consenso que justifique los poderes públicos. Con esta perspectiva, no parece extraño que Rawls ponga de relieve unos elementos contrafactuales de su doctrina, como por ejemplo la naturaleza cerrada de la sociedad o el velo de ignorancia. Estas condiciones son necesarias para clarificar las condiciones ideales de decisión acerca de qué principios, o qué órdenes sociales elegir. No se trata, como puede parecer leyendo el comienzo de Political liberalism ( Que una sociedad sea cerrada es una abstracción considerable, justificada tan sólo porque nos permita centrarnos en determinadas cuestiones principales libres de los detalles que nos distraigan». PL, p. 12), de un problema de formulación de una teoría (abstracta o trascendental) de la justicia, sino, sobre todo, de una cuestión de estabilidad de la sociedad que se rige sobre estos principios. Es decir, se trata de la posibilidad de que grupos diferentes se reconozcan como libres e iguales miembros de una unidad política y acepten como legítimo el uso de la fuerza por parte de las instituciones públicas aunque tengan diferentes concepciones, igualmente razonables, del bien y de la vida (PL, pp. 140-144). $\mathrm{Si}$ en Political Liberalism el asunto se solucionaba en el marco doméstico con el artificio del «overlapping consensus» (del consenso entrecruzado), está claro que en un ámbito de justicia internacional la cuestión es más complicada. Aquí, en efecto, faltan las instituciones liberales sobre las que se forman las concepciones del bien y de la justicia, instituciones que son condiciones necesarias para que se produzca un consenso entrecruzado en la doctrina del liberalismo político (PL, pp. $142-143,163)^{8}$. Pero se trata, sin embargo, siempre de un problema de estabilidad, es decir, que «las instituciones y prácticas entre los pueblos satisfacen los principios relevantes de justicia y equidad, aunque sus relaciones y sus éxitos cam- bian de manera constante debido a las tendencias políticas, económicas y sociales») (LP, 5.1, citada edición castellana, p. 58). El problema es determinar cuáles sean los intereses que los pueblos deben reconocerse mutuamente. Con palabras del mismo Rawls:

«un interés adicional resulta también significativo: se trata de lo que Rousseau llama amour propre (amor propio) [en cursiva en el texto], aplicado a los pueblos. Este interés es el respeto de un pueblo por sí mismo como pueblo, que se funda en su consciencia compartida sobre las peripecias de su historia y los logros de su cultura» (LP, p. 47, par. 3.3).

El respeto para la identidad de la cultura de cada pueblo ocupa una posición central para justificar la extensión de la doctrina del «derecho de gentes» a pueblos que no son liberales, pero sí son decentes, así como el respeto por las doctrinas comprensivas razonables era el eje del liberalismo político en el marco doméstico (LP, par. 7.1, p. 73) ${ }^{9}$. Este punto es fundamental para entender correctamente por qué Rawls se abstiene de presentar principios de justicia distributiva internacional: «si los pueblos liberales exigen que todas las sociedades sean liberales y se impongan sanciones políticas a las que no lo son, entonces a los pueblos no liberales decentes, si es que los hay, se les negará el respeto debido» (LP, par. 7.3, p. 74). Por esta razón Rawls no comparte la idea de que los pueblos liberales incentiven a los pueblos decentes no liberales a cambiar sus instituciones (LP, par. 11.1 y 11.3, pp. 96-100).

Creo que ahora queda claro por qué Sen se ha equivocado. La (presunta) abstención de Rawls en ofrecer principios de justicia distributiva no es debida al carácter trascendental de su teoría, sino al principio del respeto de las culturas políticas de las sociedades decentes. Pero creo que se puede también cuestionar la diagnosis 
de Sen acerca del hecho de que Rawls no nos ofrezca un principio de justicia distributiva. No es cierto, como le imputa Sen, que su doctrina se limite a presentar sólo consideraciones humanitarias. Por el contrario, Rawls tiene en cuenta la importancia de las desigualdades entre la riqueza de los distintos pueblos, pero las matiza en la medida en que se cumpla el deber de asistencia de los pueblos ricos en favor de los pueblos más pobres. Este deber se reduce a que cada sociedad tenga «un conjunto suficiente de capacidades humanas para establecer instituciones justas. (...) Una vez logrado este objetivo, el derecho de gentes no prescribe ningún fin adicional como, por ejemplo, mejorar la calidad de la vida más allá de lo necesario para sustentar las instituciones». (LP, par. 16.3, p. 138). También por esto hay razones que no derivan del carácter trascendental de su doctrina, sino de consideraciones de equidad y de respeto a las culturas políticas de los pueblos, como aparece bien claro en los dos ejemplos que nos proporciona Rawls. En ambos, las diferencias entre pueblos pobres y ricos están determinadas por decisiones políticas de las cuales son responsables los propios pueblos. Estas decisiones producen desigualdad en la distribución internacional, pero no son injustas, y desde luego no producen un deber de asistencia por parte de las sociedades más ricas, a menos que haya condiciones de pobreza extrema que impidan el mantenimiento de las instituciones justas. De todas formas hay que impedir que se produzca un incentivo para que las consecuencias de decisiones políticas equivocadas puedan ser pagadas por otros pueblos ${ }^{10}$.

\section{Hacia una teoría ideal, pero incompleta, de las valoraciones}

Hasta ahora, hemos intentado explicar por qué la teoría de Rawls no se ve in- fluenciada por los defectos que Sen imputa a las doctrinas trascendentales de la justicia.

Esto, sin embargo, no basta para proporcionar una réplica contundente a las cuestiones que Sen plantea. Es decir, parece que sí que es cierto que nuestras valoraciones no necesitan del presupuesto de un ideal. En primer lugar, me gustaría argumentar que, al contrario de lo que Sen opina, sí que es necesario que detrás de una comparación entre dos alternativas haya un modelo ideal, aunque no sea completo, es decir, que no nos ayude a valorar todas las alternativas posibles. En segundo lugar, me gustaría explicar, aunque únicamente de una manera muy superficial, como nuestras argumentaciones morales están influenciadas por el pluralismo de los valores y el particularismo ético. Para llevar a cabo esta tarea intentaré formular, en el apartado siguiente, el principio de la «determinación decreciente» de las valoraciones morales.

Hemos visto que las críticas de Sen a Rawls eran erróneas, pero no se ha dado una respuesta a la pregunta «¿Por qué es necesario presuponer unos ideales para realizar comparaciones entre alternativas?» Al final, aunque las críticas de Sen acerca de su interpretación de Rawls no eran del todo correctas, la pregunta conserva su sentido, y entonces merece una respuesta. Creo que podemos acercarnos a esta respuesta en dos pasos. En primer lugar podemos argumentar que no todos los ideales normativos implican órdenes completos de valoraciones, y en segundo lugar que el propio Sen necesita para comparar dos alternativas unos ideales, aunque sean incompletos y conflictivos.

Consideremos un caso difícil, pero común, como el siguiente: existe un país pobre, con un dictador sangriento que controla la población a través de una junta militar. La población necesita ayuda, pero es cierto que estas ayudas están bajo 
control de la junta, que se aprovecha de estos recursos para controlar más aún a la población. Las alternativas están claras:

(a) seguir ayudando a la población, (b) condicionar la ayuda al libre acceso y distribución de ésta por parte de los observadores internacionales, (c) si la junta rechaza esta condición, bloquear la ayuda hasta que la junta no acepte las condiciones dictadas. Este caso es muy familiar para los trabajadores de las organizaciones humanitarias. Intentaremos solucionarlo a través del modelo de decisión propuesto por parte de Sen. Asumimos que estamos de acuerdo, a partir de diferentes concepciones del bien, que la solución (c) sea mejor que la (b) y que la (a). ¿Qué razones podemos presentar para que se adopte (c) en lugar de (a) y (b)? Siguiendo la argumentación de Sen parece que cualquiera razón sea relevante; lo importante es llegar a un acuerdo. La posibilidad de llegar a un acuerdo parece la única condición de validez para la toma de una decisión si, tal y como parece, no tenemos ningún ideal común acerca de lo que sería bueno en esta circunstancia. Y esto parece confirmado cuando el propio Sen, como hemos visto, considera que no hay maneras de valorar los diferentes criterios de distribución. Hay naturalmente algo que falta en esta reconstrucción, y es precisamente la hipótesis de que presuponer un ideal no significa poder ordenar todas las alternativas. Por el contrario se pueden presentar ideales diferentes e incoherentes, pero todos relevantes, para decidir entre dos alternativas. Si es esto lo que Sen pone de relieve estamos de acuerdo: tal vez podemos tener dos criterios de distribución que sean ambos relevantes, pero incoherentes. Podemos no estar de acuerdo sobre cómo reorganizar el gasto público, especialmente en tiempos de crisis, porque no sabemos lo que es más urgente en un cierto momento histórico, si aumentar la productividad o de- fender los sueldos más bajos. Pero esto no significa, como parece sugerir Sen, que no debamos aclarar cuáles son los ideales que nosotros perseguimos. Sen parece equivocarse sobre las finalidades de la investigación moral: averiguar qué es lo mejor que hacer no significa que esto siempre sea lo que se deba hacer. Él no considera, sorprendentemente, que el hecho de que los ideales puedan entrar en conflicto no los hace innecesarios a la hora de valorar las alternativas.

\section{Un ejemplo creo que nos puede ayudar}

Imaginemos que somos los responsables de una misión de ayuda a una población pobre, compuesta mayoritariamente por campesinos, en un rincón de África. Nos interrogamos sobre cuáles son los ideales que intentamos realizar a través de este proyecto de cooperación. Pero, ¿por este motivo debemos asegurarnos de que tales ideales puedan solucionar todos los casos difíciles a los que podemos enfrentarnos? Puede ser que tengamos unas metas ideales (reducir la dependencia de unos campesinos de los dictados de una multinacional), pero puede ser también que estas metas no nos proporcionen soluciones a otras cuestiones, como por ejemplo si estos campesinos deben reivindicar derechos de propiedad individual. ¿Somos entonces partidarios de teorías trascendentales? Esta posibilidad no se tiene en cuenta por parte de Sen.

Aceptamos entonces que sí que es cierto que alguna vez podemos intentar alcanzar metas ideales, pero que estas metas no nos proporcionan criterios completos de valoración de otras alternativas relevantes. Esto, sin embargo, no demuestra que siempre tenemos en cuenta ideales cuando deliberamos acerca de lo que sea mejor entre dos alternativas. Al final puede ser, como Sen nos muestra, que lo que muy a menudo podemos alcanzar sean acuerdos incompletos que no 
cuestionan las razones por las cuales estamos de acuerdo. Pero éste sería una estrategia self-defeating, en el sentido que no se trataría de una deliberación sino de un hecho: que se reconoce un acuerdo, o una negociación. Sería algo que se parecería a lo que Rawls llama un «modus vivendi», y no a un consenso entrecruzado. Se trataría de un acuerdo que no tiene un particular fundamento ético, como en el caso de la deliberación, como no sea el propio hecho de que se llega a un acuerdo. Tampoco está claro por qué motivos este acuerdo podría modificarse, y extenderse su alcance. Sen no aclara, entonces, de qué manera sea posible que «el alcance del consenso respecto de clasificaciones globales pudiera por sí solo continuar extendiéndose al mismo tiempo que el proceso de interacción prosigue» (WTJ, p. 235).

Finalmente, Sen debería aclarar si su enfoque comparativo forma parte de una doctrina de la deliberación. Si es así, como yo creo, entonces es inevitable, es decir, es necesario, tener en cuenta un ideal de deliberación, aunque esto no sea suficiente para valorar todas las alternativas posibles a las que nosotros nos enfrentamos en situaciones reales ${ }^{11}$.

Se podría replicar que estos análisis no tienen en consideración el papel que juega el artificio del «espectador imparcial» que Sen introduce para presentar una forma diferente a la de Rawls de enfocar cuestiones de justicia global.

El «espectador imparcial» constituye un artificio diferente de la deliberación bajo el velo de ignorancia. En primer lugar se trata de una persona que no imagina que forma parte de la sociedad en la que se lleva a cabo una deliberación. En segundo lugar, el espectador imparcial no decide sobre lo que una teoría ideal de la justicia pretende, sino que valora cuál entre dos, o más, alternativas realiza, o retarda un principio de justicia ${ }^{12}$. Y final- mente el espectador imparcial puede valorar las alternativas en función de cualquier perspectiva, aunque esto sea propio de sociedades muy alejadas en el tiempo y en el espacio (WTJ, pp. 230-231).

Pero, ¿este artificio no presupone unos ideales? El mismo Sen, en su producción anterior dedica muchas páginas a desmontar la naturaleza supuestamente formal y abstracta de las doctrinas utilitaristas. Detrás de la imagen de la persona que decide de forma racional e imparcial, se esconde la idea de que todas las preferencias tienen un mismo valor, no importa sus contenidos. Y esta presunción tiene un alto precio, dejar que el ámbito de la moral se quede reducido a lo que se pueda querer en un momento dado, no importa cómo formemos nuestros deseos o lo que deseemos ${ }^{13}$. Pues, si Sen se toma en serio su idea de que se pueda evaluar sin tener en cuenta unos ideales, aunque sean incompletos, entonces regresaría a aquellas posturas que tanto ha criticado en el pasado.

\section{Para una conclusión "particularista»}

Creo que se pueden resumir en dos las conclusiones de este trabajo, antes de intentar presentar algunas notas sobre una teoría metaética que pueda tener en cuenta las cuestiones que Sen ha planteado.

En primer lugar, hay que reconocer que, como a menudo puede pasar, éste nos proporciona una versión equivocada de la teoría de Rawls. Sen imputa a la doctrina de la justicia como equidad, así como a la teoría del liberalismo político y del derecho de las gentes, defectos que en realidad estas doctrinas no tienen, o, mejor dicho, que son el resultado de interpretaciones parciales de una construcción teórica de enorme alcance.

En segundo lugar, la propia teoría metaética de Sen es, al final, menos clara de lo que parece. La distinción entre en- 
foques transcendentales y comparativos de los asuntos de justicia no es correcta por dos aspectos. No es cierto que los ideales no sean necesarios para hacer valoraciones, y tampoco utilizar unos ideales equivale a presentar doctrinas que pretendan ordenar todas las alternativas.

Esto no quiere decir que Sen no plantee cuestiones importantes. Es verdad que muy a menudo no tenemos en cuenta lo que podemos pedir a las doctrinas de la justicia, es decir, cuáles son las condiciones para valorar los juicios morales que formulamos ${ }^{14}$. En este apartado final intentaré ofrecer algunas notas a este propósito.

A pesar de lo que parece opinar Sen, creo que uno de los logros del pensamiento filosófico político contemporáneo viene dado por la reconstrucción de cómo se pueda aplicar una doctrina ideal de la justicia (una forma de justicia procedimental pura) a instituciones y decisiones reales, y entonces imperfectas, a través de una secuencia en cuatro estadios. Bajando de un nivel a otro podemos tener en cuenta siempre más informaciones, es decir, podemos deliberar teniendo en cuenta condiciones reales que antes, en el nivel más alto, no eran relevantes. Un ejemplo es el hecho de que en el nivel constitucional no debemos tener en cuenta nuestras concepciones del bien, o mejor dicho debemos persuadirnos de que nuestras concepciones son compatibles con las que otros miembros iguales y libres de la comunidad puedan tener, mientras que sí lo podemos hacer, con algunas limitaciones como las dictadas por el principio de no-discriminación, cuando intentamos deliberar sobre asuntos de gasto público. Este ámbito puede ser aún más amplio cuando estamos implicados en evaluar cuál es la educación que queremos dar a nuestros hijos. En este caso, no sólo tenemos en cuenta nuestras convicciones morales, sino también previsiones acerca de lo que sea ne- cesario para sus vidas en la sociedad ${ }^{15}$. Nuestras deliberaciones creo que se puedan plantear bajo la misma secuencia: cuanto más concreta es la decisión, más amplio será el ámbito de las informaciones relevantes ${ }^{16}$.

Como hemos visto antes, el aumento de la información relevante conlleva como consecuencia el riesgo de que en muchas ocasiones nuestros juicios morales no sean determinados. Por esta razón, el propio Rawls admitía que su doctrina era indeterminada: a la hora de decidir qué distribución elegir podemos no tener un argumento concluyente. Pero, como Sen muestra, tenemos que elegir, es decir, tenemos que valorar y ordenar alternativas, aunque nuestras doctrinas no sean completas, y, algunas veces, ni siquiera coherentes. La solución no es eliminar algún tipo de información considerándola como irrelevante para valorar dos alternativas. En este caso, tendría razón Sen, y pagaríamos un precio muy alto: hacer abstractas nuestras doctrinas morales.

Pero hay otra salida. Es posible limitar nuestras pretensiones acerca de las doctrinas morales, y aceptar lo que llamo el principio de «determinación decreciente»: aumentar el nivel de información relevante para la valoración aumenta el riesgo de indeterminación, y la posibilidad de que no se puedan ordenar todas las alternativas. El mismo enfoque de la justicia según las capacidades creo que comparte este principio, mostrando que la exhaustividad del utilitarismo se paga con la reducción del nivel informativo. Pero, ¿por qué aumenta la indeterminación? No es sólo el número de las variables, ni siquiera el simple hecho de que haya diferentes culturas, sino que la información es relevante en función de valores que tenemos en cuenta en nuestras deliberaciones y ocurre que, algunas veces, no podemos poner en práctica estos valores al mismo tiempo. 
Volviendo a los casos que hemos presentado en el apartado dos, está claro que las políticas de desarrollo se enfrentan a casos trágicos, pero esto no es, creo, sólo el resultado de situaciones no ideales de deliberación, sino que, también, queremos poner en práctica valores que pueden entrar en conflicto. $\mathrm{Y}$ que estos conflictos se presentan a menudo en situaciones concretas, es decir, en casos particulares de aplicación de los principios generales ${ }^{17}$. Las doctrinas de la justicia, entonces, no pueden presentarse como teorías que intentan formular proposiciones acerca de valores que en algu- nas circunstancias pueden no realizarse mutuamente ${ }^{18}$. Por lo tanto, estas doctrinas no pueden ser indeterminadas y particularistas, puesto que se trata de doctrinas que ofrecen soluciones a conflictos entre principios o valores que valen sólo para casos particulares ${ }^{19}$. Por esta razón, creo que, para tener en cuenta las importantes notas que Sen nos ha ofrecido, tenemos que asumir el riesgo de formular doctrinas morales que sean ideales, es decir, que pretendan estar justificadas, y no sólo aceptadas, pero al mismo tiempo que admitan que son incompletas y válidas en particulares circunstancias.

\section{NOTAS}

\begin{abstract}
* Agradezco a Lucía Aparicio Chofré por revisar mi castellano y al profesor Jesús Ballesteros por leer una versión precedente. Soy el único responsable de los posibles errores y omisiones contenidos en este artículo.
\end{abstract}

1 Sen, A.K., "What do we want from a theory of justice?», in Journal of philosophy, CIII, 5, 2006, pp. 215-238. Desde ahora, WTJ.

2 Rawls, J., A theory of justice (1971), revised edition, Oxford, Oxford University Press, 1999, pp. 23 , 453. Desde ahora TJ.

3 Rawls, J., Political liberalism, New York, Columbia University Press, 1993, p. 12. Desde ahora PL.

4 Ya en Inequality reexamined, Oxford, Clarendon Press, 1992, p. 78, Sen había presentado unas críticas similares a Rawls: al considerar la existencia de instituciones liberales una conditio sine qua non para pedir el respecto de las condiciones mínimas de justicia distributiva. He intentado exponer algunos límites de esta polémica en Biondo, F., Benessere, giustizia e diritti umani nel pensiero di Amartya Sen, Torino, Giappichelli, 2003, pp. 109-118.

5 Véase como ejemplo de una, a mi juicio, equivocada aceptación del modelo del liberalismo político de Rawls, Biondo, F., «Is Martha Nussbaum really political liberal?», in Archiv für Rechts-und Sozialphilosophie, 3, 2008, pp. 311-324.

6 Sin embargo, la postura de Rawls sobre este punto no está clara. En otras ocasiones, éste afirma: «A primera vista la doctrina del contrato puede aparecerse como asistemática sin remisión (...). Pero hay otras formas de unidad teorética aparte de aquellas definidas por principios completamente generales. Podría suceder que encontráramos una secuencia adecuada de tipos de sujeto y supusiéramos que los partidos que comparecen en el contrato social han de proceder por medio de dicha secuencia y con el conocimiento de que los principios de cualquier acuerdo posterior han de quedar subordinados a aquéllos referidos a todo acuerdo anterior, o, de otro modo, ajustados a los mismos por medio de reglas de prioridad determinadas». PL, p. 262. Aquí parece que el resultado de las decisiones tomadas bajo el velo de ignorancia sean obligatorias para las partes cuando se debe deliberar.

7 A pesar de la interpretación «trascendental» del pensamiento de Rawls que nos ofrece Sen, la mayor parte de la doctrina se ha planteado la cuestión de la falta de exhaustividad de la doctrina rawlsiana de la razón pública. Véase Schartzman, M., «The completeness of public reason», in Politics, Philosophy and Economics, 3, 2004, pp. 191-220.

8 Véase también Rawls, J., Law of the people, Harvard, Harvard University Press, 1999, par. 1.2, El derecho de gentes, traducción cast. que se cita de H. Valencia Villa, Paidós, Barcelona, 2001, desde ahora LP; y Biondo, «Is Martha Nussbaum really political liberal?», cit., pp. 317-320.

9 Esto claramente no significa que la doctrina de Rawls sea aceptable, en todo o en parte. Es decir, alternativamente es posible que su doctrina sea justa en principio pero no logre distinguir entre sociedades liberales y sociedades decentes, o que no sea conceptualmente, y también normativamente, posible distinguir entre los dos tipos de sociedades. Prefiero no tomar parte en este largo debate.

10 Sobre este riesgo, que tampoco Sen tiene en cuenta, me permito reenviar a Biondo, Benessere, 
giustizia e diritti umani nel pensiero di Amartya Sen, cit., pp. 110-111.

11 Sobre el carácter necesariamente ideal de las deliberaciones me permito reenviar a un debate entre Josep Lluis Martí Mármol y yo en Ragion Pratica 32, 2009, pp. 231-273.

12 «(...) Los observadores imparciales de Smith son mencionados habitualmente con el propósito de contrastar alternativas que arrojen luz sobre cuestiones específicas de avance o retroceso de la Justicia dentro de la aproximación comparativa». WTJ, p. 230. Por supuesto, esta postura tiene sentido sólo si asumimos que la justicia, de la que se habla, se considera no como un ideal, sino como una estipulación. Claramente esto aumenta las dificultades teóricas de una doctrina que considera que no es necesario deliberar sobre ideales.

13 Me permito reenviar, de nuevo, a Biondo, $\mathrm{Be}$ nessere, giustizia e diritti umani nel pensiero di Amartya Sen, cit., pp. 17-20.

14 La misma teoría de Rawls me parece un ejemplo de lo que he escrito. No está claro su enfoque metaético: si su constructivismo moral es más afín a una forma de realismo moral, o a una forma de convencionalismo.

15 Creo que el hecho de que las familias no tengan suficiente información para decidir cuáles sean las competencias necesarias para sus hijos es una de las justificaciones de la educación pública y obligatoria. Que el Estado decida cuál sea el contenido de todas las asignaturas es otra cuestión, hoy muy debatida.

16 Para un ejemplo de este proceder de justificación, véase Daniels, N., Just Health Care, Cambridge, Cambridge University Press, 1985, pp. 94-95, n. 103; Daniels, N., Justice and justification. Reflective equilibrium in theory and practice, Cambridge, Cambridge University Press, 1996, p. 193.

17 Creo que desde esta perspectiva se podría ofrecer un diagnóstico diferente del hecho de que el nivel más bajo de la secuencia, el del respecto y de la apli- cación de las leyes, está conectado por una parte con el caso de la justicia procedimental imperfecta (TJ, pp. 74-75) y por otro con los problemas de la desobediencia civil (TJ, pp. 319 ss.). En ambos casos veremos cómo principios ideales pueden realizarse de forma insuficiente en instituciones reales. Pero, no está claro si, como opina Rawls, el problema sea sólo de conocimiento imperfecto de los hechos, por una parte, e imperfecta realización de los principios de igual libertad, por otra; o no sea, como yo creo, un conflicto entre diferentes valores. En el primer caso, se trataría de respetar algunos procedimientos legales que limitan la recogida de pruebas, aunque esto pueda hacer más difícil llegar a la verdad. En el segundo caso, se trata de no rebelarse de manera eficaz contra las leyes injustas en una sociedad casi justa aunque estas injusticias dañen a unas mayorías perpetuas. No es una casualidad que J. Feinberg [«Rawls and Intuitionism», in Daniels, N. (ed.), Reading Rawls, Oxford, Blackwell, 1975, pp. 116-124] considere la justificación de la desobediencia civil como un caso de intuicionismo en la doctrina de Rawls en el sentido de que no hay una jerarquía determinada entre los principios a este respecto.

18 En teoría del derecho se ha desarrollado en estos años un extenso debate sobre las características de la ponderación entre principios constitucionales. Se habla, a este respecto, de jerarquía axiológica móvil (gerarchia assiologica mobile), es decir la ponderación está justificada sólo para el caso particular, si ocurren otras condiciones se puede justificar otra ponderación. Véase Celano, B., «Defeasibility e bilanciamento. Sulla imposibilità di revisioni stabili», in Ragion Pratica, 18, 2002, pp. 223-239.

19 Hay otra justificación del particularismo como doctrina metaética: que la decisión de si un caso es análogo a otro, y si está regulado por una cierta norma, es siempre una decisión particular. Véase Celano, B., «Pluralismo etico, particularismo e caratterizzazioni di desiderabilità: il modello triadico», in Ragion Pratica, 26, 2006, pp. 137-138. 